\title{
Use of a High-Resolution Sodar to Study Surface-layer Turbulence at Night
}

\author{
Stefania Argentini - Giangiuseppe Mastrantonio • \\ Igor Petenko · Ilaria Pietroni · Angelo Viola
}

Received: 20 October 2010 / Accepted: 7 July 2011 / Published online: 26 July 2011

(C) The Author(s) 2011. This article is published with open access at Springerlink.com

\begin{abstract}
Measurements in the atmospheric surface layer are generally made with point sensors located in the first few tens of metres. In most cases, however, these measurements are not representative of the whole surface layer. Standard Doppler sodars allow a continuous display of the turbulent thermal structure and wind profiles in the boundary layer up to $1000 \mathrm{~m}$, with a few points, if any, in the surface layer. To overcome these limitations a new sodar configuration is proposed that allows for a higher resolution in the surface layer. Because of its capabilities (echo recording starting at $2 \mathrm{~m}$, echo intensity vertical resolution of approximately $2 \mathrm{~m}$, temporal resolution of $1 \mathrm{~s}$ ) this sodar is called the surface-layer mini-sodar (SLM-sodar). Features and capabilities of the SLM-sodar are described and compared with the sodar. The comparison of the thermal vertical structure given by the SLM-sodar and the sodar provides evidence that, in most cases, the surface layer presents a level of complexity comparable to that of the entire boundary layer. Considering its high vertical resolution, the SLM-sodar is a promising system for the study of the nocturnal surface layer. The nocturnal SLM-sodar measurements have shown that, depending on wind speed, the structure of the surface layer may change substantially within a short time period. At night, when the wind speed is greater than $3 \mathrm{~m} \mathrm{~s}^{-1}$, mechanical mixing destroys the wavy structure present in the nocturnal layer. Sonic anemometer measurements have shown that, in such cases, also the sensible heat flux varies with height, reaching a peak in correspondence with the wind speed peak. Under these conditions the assumption of horizontal homogeneity of the surface layer and the choice of the averaging time need to be carefully treated.
\end{abstract}

Keywords Micrometeorology $\cdot$ Sodar $\cdot$ Surface layer $\cdot$ Thermal turbulence

S. Argentini $(\varangle) \cdot$ G. Mastrantonio · I. Petenko · I. Pietroni · A. Viola

ISAC-CNR, Via del Fosso del Cavaliere, 100, 00133 Rome, Italy

e-mail: stefania.argentini@artov.isac.cnr.it

I. Petenko

IAPh RAS, Pyzhevskiy, 3, 109117 Moscow, Russia 


\section{Introduction}

Numerical models still encounter problems in capturing atmospheric phenomena at scales from a few metres to a few hundreds of kilometres, especially during stably stratified nocturnal conditions overland (Gryning 1985; McNider et al. 1995; Poulos and Bossert 1995; Seaman 2000). Actually most surface-layer parametrizations in numerical models rely on the Monin-Obukhov similarity theory, which is more appropriately applied to the weakly stable, neutral, and convective boundary layers (Derbyshire 1995). Quantitative formulations of the nocturnal surface layer (hereafter NSL) require a deeper understanding of the processes responsible for the turbulent burst activity associated with non-stationarities due to shearflow instabilities, the presence of Kelvin-Helmholtz and internal gravity waves of different origin, surface heterogeneity, sensible heat and radiative flux divergence. The characteristics of the spatial and temporal fine structure of the NSL need to be studied, and the way in which these structures modify the surface fluxes investigated in order to develop more appropriate parametrizations for the NSL. For these studies it is necessary to use sensors that operate continuously and have a high temporal-spatial resolution.

The sodar is an appropriate system for studying turbulence in the atmospheric boundary layer, even though commercial sodar systems do not have the desirable resolution in the surface layer and they present a blind zone of some tens of metres close to the ground. When voice-coil-based electro-acoustic transducers are used, the blind zone is mainly caused by the residual oscillation (ringing) of the membrane just after the emission of the acoustic tone. The ringing obscures the atmospheric echoes if the same transducer is used to emit the tones and receive the echoes. Mursch-Radlgruber et al. (1994) present the results of the observations made with a NOAA portable high frequency mini-sodar consisting of a four-array antenna system (each consisting of 25 piezo-electric elements) installed vertically and operating at $6.5 \mathrm{kHz}$. The minimum height investigated was $5 \mathrm{~m}$, with a vertical resolution of $5 \mathrm{~m}$. Asimakopoulos et al. (1987) highlight the importance of using high frequency mini-sodars with piezo-electric transducers in the study of the atmospheric surface layer. They used an operating frequency of $3.5 \mathrm{kHz}$ to monitor the boundary layer up to $150 \mathrm{~m}$ starting at $1 \mathrm{~m}$ from the ground. By using electro-acoustic voice-coil transducers and high frequencies, Weill et al. (1986), Kouznetsov (2009) and Bonner et al. (2009) demonstrated that it is possible to record echoes at a distance within $10 \mathrm{~m}$ of the ground.

Although the piezo-electric transducers have a much shorter ringing time and can be used to reduce the blind zone, they cannot handle a high acoustic power and are usually assembled in a phased array. The phased array setting poses a limitation on the frequency that can be used; when high frequencies are used, the ratio $d \lambda^{-1}$ of the transducer distance $d$ and the wavelength $\lambda$ should not be close to or larger than 1 , otherwise a large portion of the energy is lost from the sidelobes (Mursch-Radlgruber et al. 1994).

In order to overpass the limitations of the piezo-electric transducers, to reduce the blind zone, and to maintain good vertical resolution a high-resolution Doppler sodar was developed that uses voice-coil-based electro-acoustic transducers. This sodar was named the surfacelayer mini-sodar (hereafter SLM-sodar) because its vertical and temporal resolutions and the first level of sounding satisfy the conditions necessary in the study of the surface layer. The SLM-sodar is a particular setting of the system described by Contini et al. (2007) in which the electronics have been improved and reduced to their essential components. The system is modular and, by using appropriate antennae and frequencies, it may operate alternately as a mini-sodar or as a standard sodar.

In Sect. 2, the features of the new system are given, and in Sect. 3, a description of the experiment is given, together with a comparison between the SLM-sodar and sodar 
echograms. In Sect. 4, an application of the SLM-sodar to the study of the spatial and temporal structure of the turbulence in the NSL is described.

\section{The SLM-Sodar: Technical Details}

In recent years a modular multi-tone Doppler sodar was developed at the ISAC-CNR Institute in which all functions are handled by a personal computer and where two commercial electronic cards are used to handle the tone generation and the echo acquisition (Contini et al. 2007). Software, developed on the LabWindow platform, takes care of all sodar functions amongst which are the timing, the digital filtering, the signal processing, the wind-field and echogram visualizations. Each card controls two channels (inputs and outputs) and, if appropriate antennae are used, the system can operate at high frequencies (mode mini-sodar) or at low frequencies (mode sodar). The tone emission, the echoes reception and processing are handled separately for each antenna/channel. The electronic parts are minimized; only an antenna preamplifier and a power amplifier for the burst amplification are used.

This system modularity has allowed us to easily construct the SLM-sodar, which is a minisodar configured for the study of the atmospheric surface layer. In the SLM-sodar a tone with a frequency of $5 \mathrm{kHz}$ and duration of $10 \mathrm{~ms}$ is synthesized. The signal is then sent to three power amplifiers and then emitted into the atmosphere by three vertically pointing antennae. Three emitting antennae were used to increase the signal intensity and consequently the signal-to-noise ratio. These antennae are placed symmetrically around the antenna that is used to receive the scattered echoes. The reflected signal, after being pre-amplified, is digitized at $3.86 \mathrm{kHz}$ with a second card, digitally filtered and analyzed. The separation of the chains of transmission and reception implies the minimization of the electronic cross-talk between the channels. Figure 1 shows the location of the antennae with detail of the receiving antenna.

The burst is emitted each $1 \mathrm{~s}$, implying an operative range of approximately $170 \mathrm{~m}$. The first range gate (a layer $5.6 \mathrm{~m}$ thick) starts at $2 \mathrm{~m}$ and the vertical resolution is approximately $1.7 \mathrm{~m}$. The method to obtain the vertical velocity field is that described in Mastrantonio and Fiocco (1982), and the influence of the ambient noise was reduced using the two-step method suggested by Mastrantonio and Argentini (1997). The reduction achieved in the environment acoustic noise is shown in Fig. 3 of Mastrantonio and Argentini (1997). To increase the accuracy in the estimate of the radial wind, the technique proposed by Contini et al. (2004) was used. This technique corrects the signal by applying the electro-acoustic transducer transfer function.
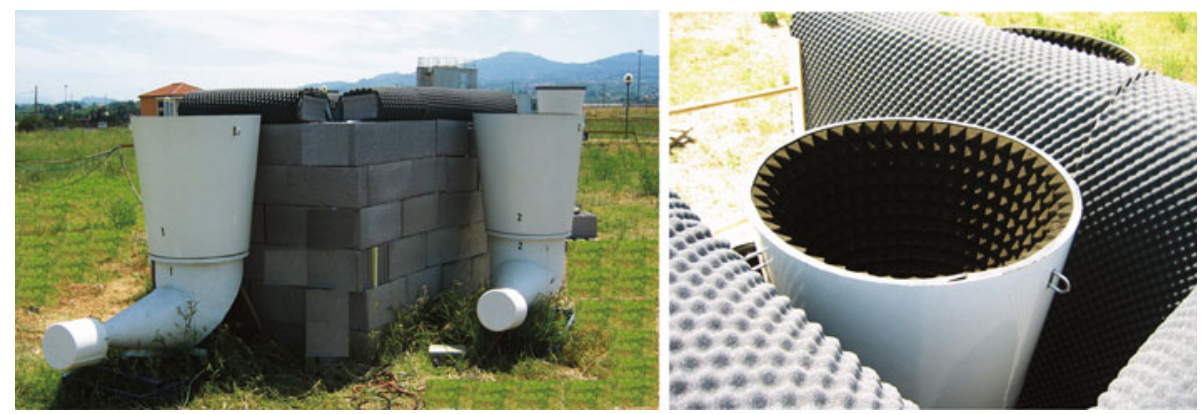

Fig. 1 SLM-sodar antennae arrangement, and details of the receiving antenna 


\section{Comparison of the SLM-Sodar, Sodar and Sonic Anemometers}

The SLM-sodar performances are compared with those of the sodar in one experiment made at the ISAC-CNR research area $\left(41^{\circ} 50^{\prime} \mathrm{N}, 12^{\circ} 38^{\prime} \mathrm{E}\right)$, located $100 \mathrm{~m}$ a.s. $1.25 \mathrm{~km}$ from the Tyrrhenian sea. At $10 \mathrm{~km}$, in the south-east direction, the Albani hills (mean altitude $600 \mathrm{~m}$; max altitude $1000 \mathrm{~m}$ ) are located, while $20 \mathrm{~km}$ in the north-west direction lies the great urban centre of Rome. The results presented in this study refer to the period August-September 2008 .

\subsection{The Experimental Set-Up}

Beside the SLM-sodar, a sodar and three sonic anemometers were placed in the experimental field. The sodar is a triaxial monostatic Doppler system, radiating acoustic bursts simultaneously, each at a different frequency $(1750,2000$ and $2250 \mathrm{~Hz})$. The use of different frequencies avoids the cross talk between the antennae and allows for a one-step spectral analysis (Mastrantonio and Argentini 1997). The procedure to obtain the Doppler shifts of the emitted frequencies is described in Mastrantonio and Fiocco (1982), while the tone bursts, emitted every $6 \mathrm{~s}$, allow for an instrumental range of $1000 \mathrm{~m}$. The aerial view of the experimental site (Fig. 2) shows the positioning of:

- three sodar antennae (number 4: vertical antenna, numbers 5 and 6: tilted antennae),

- a 15-m meteorological tower (number 1) with two sonic anemometers model Gill Solent R50 (Contini et al. 2006) at heights of 7 and $15 \mathrm{~m}$,

- a 3.5-m mast (number 2) with a sonic thermo-anemometer (Metek USA-1) at the top.

The SLM-sodar (number 3) was located half way between the meteorological tower and the mast.

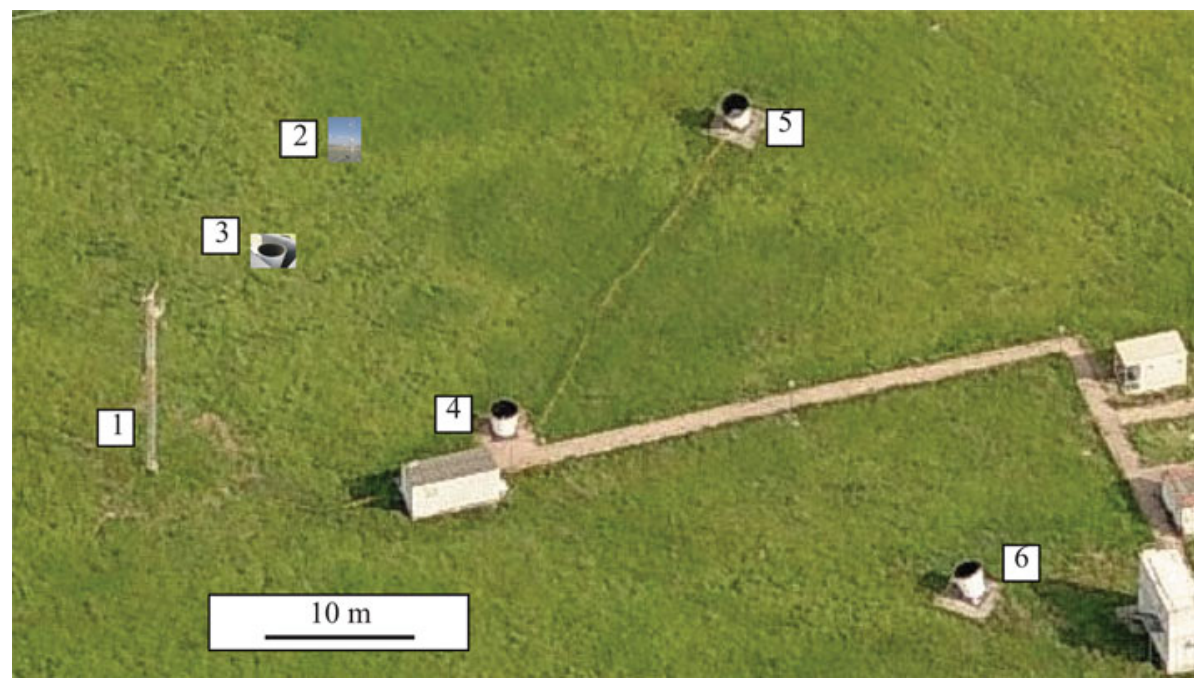

Fig. 2 Aerial view of the ISAC/CNR experimental facility in Rome. Meteorological tower (1); meteorological mast (2), SLM-sodar (3), Doppler sodar antennae (4, 5, 6) 
3.2 Comparison Between the SLM-Sodar and the Sodar: The Turbulent Thermal Structure

The thermal turbulent structure of the atmosphere is depicted with a high level of temporal and spatial resolution by the so-called echogram that shows, in grey levels, the intensity of the backscattered signal. Figure 3a shows an example of the surface-layer thermal structure as "seen" by the SLM-sodar during a cloudless night. Since the echo recording starts immediately after the tone-burst emission, the echogram allows us to visualize the atmospheric thermal structure from a height of about $2 \mathrm{~m}$. The details of the surface-layer thermal structure are clearly evident. The straight grey line at about $20 \mathrm{~m}$ is a fixed echo produced by the presence of the 15-m meteorological tower. The 30-min averaged wind profiles (in green), given by the triaxial Doppler sodar (first measurement at $70 \mathrm{~m}$ ) and by the sonic anemometer at $3.5 \mathrm{~m}$, are superimposed. The red crosses represent the wind direction.

Figure 3 b shows, instead, the boundary-layer thermal structure as "seen" by the sodar. The sodar wind profiles are the same of those in Fig. 3a, but extend up to $500 \mathrm{~m}$, and show the presence of southerly air masses above $150 \mathrm{~m}$ after 0000 solar time (ST). Flows from different directions are separated by an "interface zone". Starting from 0200 ST, the same airflow is observed only above $300 \mathrm{~m}$. The vertical displacement of the interface zone enables the crossing of the air masses arriving from different directions through the surface-layer measurement sensors. Sudden variations of the airflow sensed by the ground sensors could not be easily explained, and erroneously attributed to horizontal inhomogeneities of the probed scalar quantity if the SLM-sodar measurements were not available. Echograms with thin thermal turbulent layers in the first $20 \mathrm{~m}$, were often observed during cloudless fair weather nights.

In the first few tens of metres no echoes are drawn. The black horizontal band below $30 \mathrm{~m}$ is due to the ringing of the electro-acoustic transducer membrane after the tone-burst emission. The ringing duration depends on the emitted frequency, the transducer characteristic, and the atmospheric parameters (Contini et al. 2004). This "ringing band" is absent on SLM-sodar echograms because the emitting and receiving circuits are kept separate.

An important piece of information that we get comparing Fig. $3 \mathrm{a}$ and $\mathrm{b}$ is that the thermal structure of the surface-layer, presents a level of variability comparable to that of the entire atmospheric boundary layer.

Figure 4 shows the echogram (red), with the vertical wind velocities superimposed (black), for some hours characterized by convective activity (September 7 between 0800 and 1200 ST). The figure evidences a good coherence between the echogram, and the vertical velocities, starting from the layers close to the ground. The first vertical velocity value is associated to an atmospheric layer centred at $7 \mathrm{~m}$, that we could not show with a lower vertical resolution.

Considering the potential of the SLM-sodar we believe that this system is a valid support in the study of the surface-layer inhomogeneities, and in all the issues related to the study of the vertical structure of turbulence in the surface-layer (turbulent fluxes, pollutants dispersion, vertical diffusion, etc.).

\section{Application of SLM-Sodar to the Study of the Nocturnal Surface-Layer}

It is commonly assumed that "the horizontal homogeneity and stationarity are more easily realized in the surface layer than elsewhere in the atmospheric boundary layer" (Kaimal and Finnigan 1994). Based on this assumption most of the parametrizations regarding the turbulent exchange between the surface and the atmosphere rely on the concept of a fluxgradient correspondence underlying heat/mass transfer laws, and on the assumption that the 
Direction
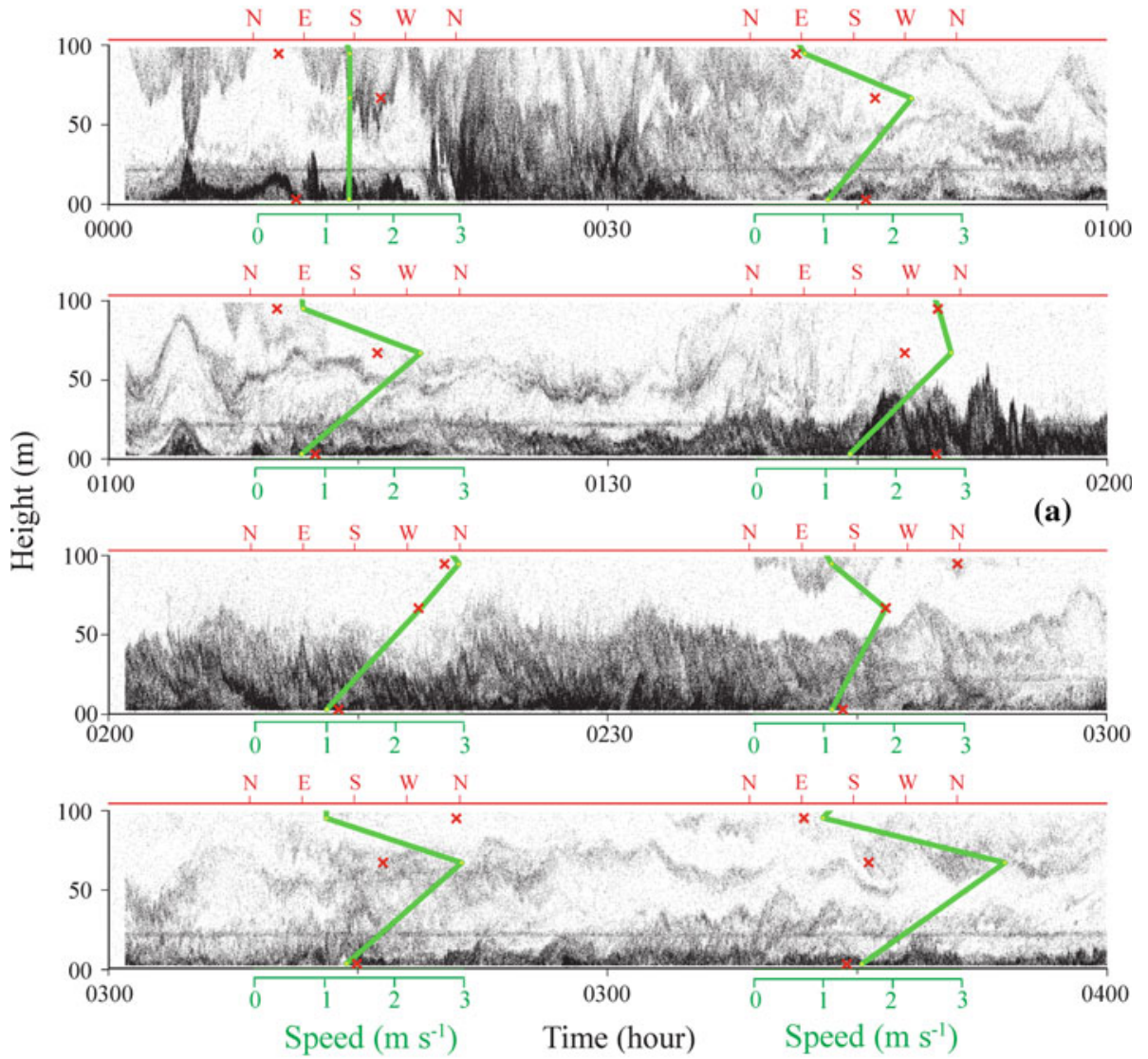

Direction

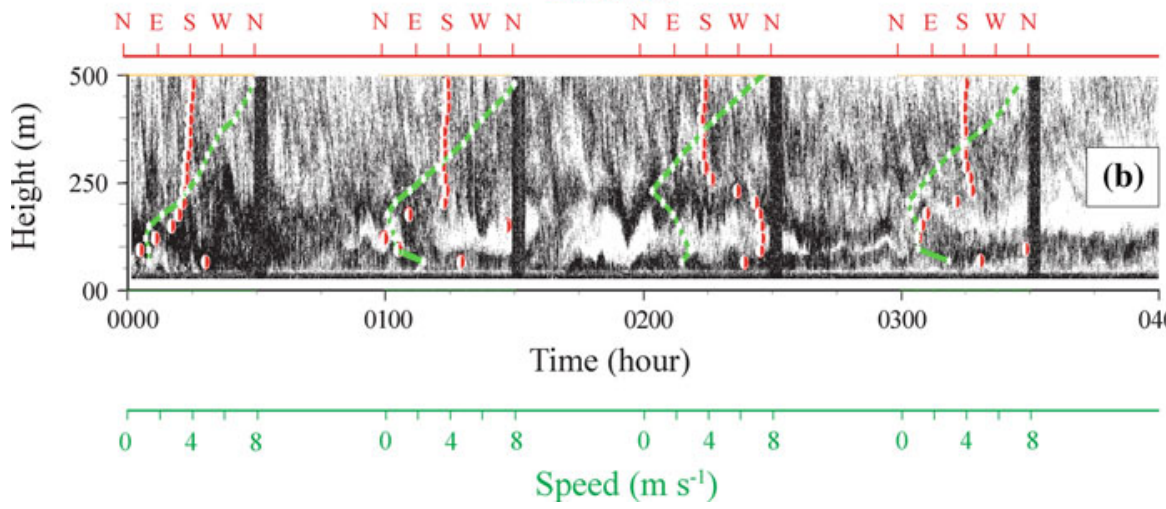

Fig. 3 Surface-layer thermal structure recorded during a night characterized by low winds (September 7, 2008 0000-0400 ST). a SLM-sodar, b sodar. The wind profiles measured by the Doppler sodar and by the sonic anemometer on the $3.5 \mathrm{~m}$ mast, are superimposed. The green lines represent the wind speed, with the red crosses/dots indicating the wind direction 

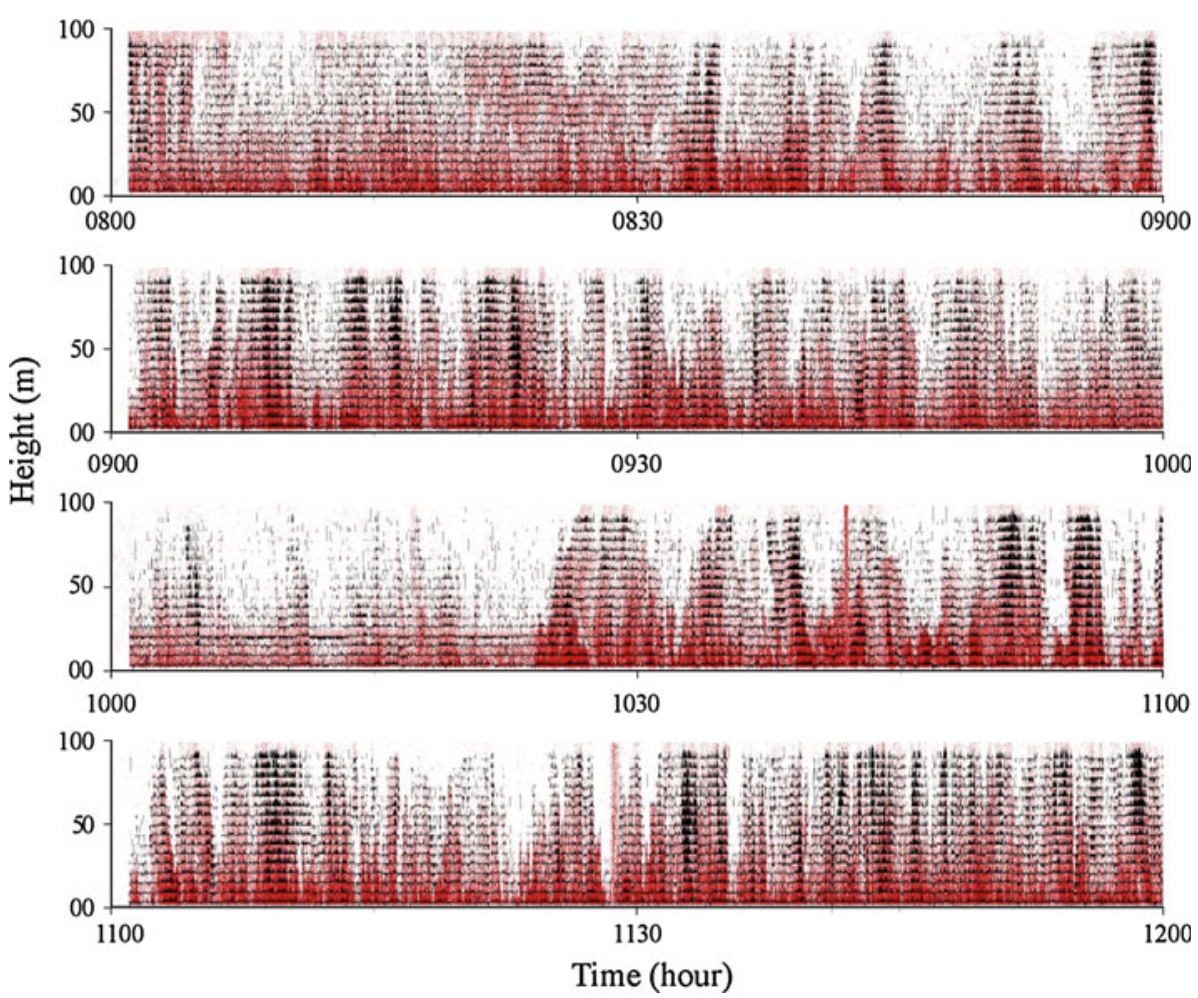

Fig. 4 Details of a convective surface layer recorded by the SLM-sodar on September 9, 2008 0800-1200 ST. The echogram (red) and vertical wind field (black) are shown. The vertical wind normalization is chosen so that a vertical wind speed of $3 \mathrm{~m} \mathrm{~s}^{-1}$ corresponds in the graph to the distance between two range-gates

velocity and scalar gradients exist only in the vertical. Local homogeneity may be found in non-complex terrain, under fair weather conditions during daytime and under stationary conditions. Lee et al. (2004) have expressed the need for extensive tests of the validity of such an idealization. They also considered a scanning solar blind water Raman lidar as a possible tool to test the concept of surface-layer horizontal homogeneity and stationarity. From our studies with the SLM-sodar it appears that the assumption of local homogeneity for the surface layer may not be assumed in a large number of circumstances, especially for the NSL at high wind speeds $\left(>3 \mathrm{~m} \mathrm{~s}^{-1}\right)$. We believe that the SLM-sodar will help in improving the knowledge of the NSL, having the possibility to monitor with continuity and with the needed vertical resolution the evolution of the structure of this layer. The questions that are relevant include, (1) To what extent does the thermal structure depicted in the sodar echograms represent surface-layer processes? (2) Which are the meteorological and turbulent parameters influencing the NSL thermal structure, and surface fluxes? In the following some preliminary results of a NSL study for the period August-September 2008 carried out using in situ sensors for turbulence measurements (sonic anemometers), the SLM-sodar, and a Doppler sodar are described.

The probability distributions of the wind speed, sensible heat flux and vertical velocity standard deviation, measured between 2200 and 0400 ST by the sonic anemometers, were analyzed in order to study the background conditions of the NSL. The results are shown in 

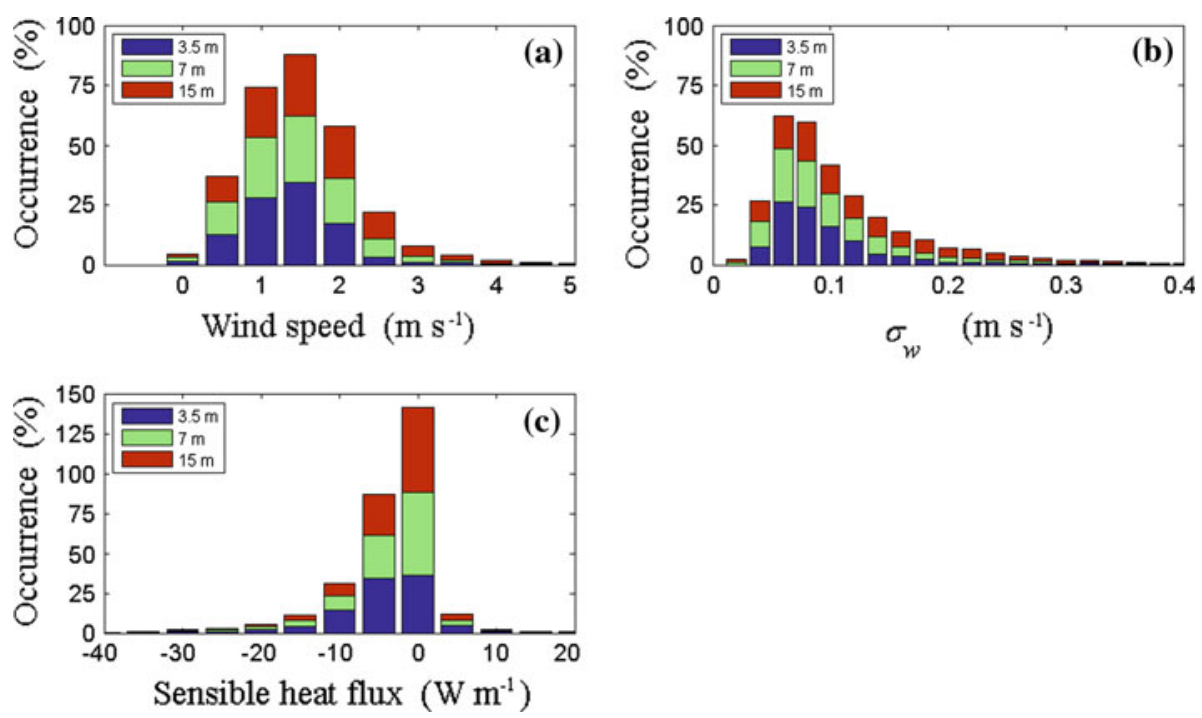

Fig. 5 Normalized distributions of the a wind speed, b vertical velocity standard deviation, $\mathbf{c}$ sensible heat flux, for the three sonic anemometers. Different colours refer to the different measurements heights

Fig. 5a-c, each graph showing the distribution of the given parameter at the height at which the measurement was made ( $3.5 \mathrm{~m}$-blue, $7 \mathrm{~m}$ - green, $15 \mathrm{~m}$-red). The wind speed (Fig. 5a) ranges between $0-5 \mathrm{~m} \mathrm{~s}^{-1}$, with a peak at $1.5 \mathrm{~m} \mathrm{~s}^{-1}$ at all levels. The kurtosis decreases with altitude. At $15 \mathrm{~m}$ the behaviour of the distribution is symmetric around the peak. The standard deviation of the vertical velocity (Fig. 5b) ranges between 0.02 and $0.4 \mathrm{~m} \mathrm{~s}^{-1}$, and only occasionally exceeds this value at $15 \mathrm{~m}$. The distributions show peaks at 0.05 and 0.075 $\mathrm{m} \mathrm{s}^{-1}$, respectively, with the peak value decreasing with height, whereas the occurrence of data in the right tail increases with height. The sensible heat, as shown in Fig. 5c, is mostly between -15 and $5 \mathrm{~W} \mathrm{~m}^{2}$, with measured values rarely out of this range. At all levels the peak is observed in the bin centred at zero, but the frequency of occurrence at the height of $3.5 \mathrm{~m}$ is lower than at other levels. The distributions of the sensible heat flux at 7 and $15 \mathrm{~m}$ are very similar. For the entire period under investigation the nocturnal echograms, from 2200 to $0400 \mathrm{ST}$, were examined and the records showing similar thermal structures were grouped. Two main patterns were identified: stratified layers with waves (hereafter WA) and high frequency "vertical spikes" (hereafter VS). The VS structures, due to mechanical mixing, have a shape similar to that of convective plumes but are characterized by a greater variation in frequency. The behaviour of the meteorological parameters (wind speed and direction) and other relevant turbulent quantities (heat fluxes, vertical velocity standard deviation, friction velocity) were examined in correspondence of these patterns in order to study the correlation between the thermal turbulent patterns and the surface-layer meteorological and micrometeorological parameters. As an example of WA structures, the facsimile record of the day 6 August 2008, at 0200-0300 ST (Fig. 6), is shown. The depth of the layer affected by the turbulent activity is small (for most of the time less than $50 \mathrm{~m}$ ), with waves of different amplitude and duration depending on the height. Structures of this type are observed during clear nights with weak synoptic forcing when the local circulation prevails. The time series of the main turbulent quantities are shown in Fig. 7a-d, with different marks referring to different measurement levels. The sensible heat flux oscillates around zero (Fig. 7a). 


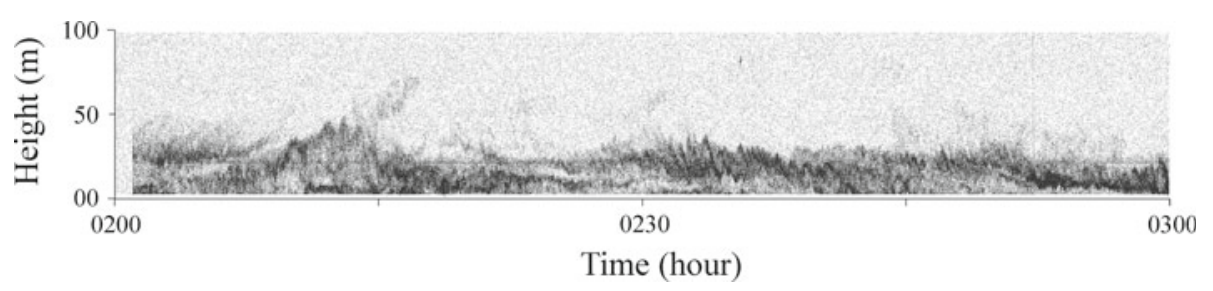

Fig. 6 SLM-sodar facsimile recording for 6 August 2008 0200-0300 ST. The thermal structure is confined to a 50-m deep layer. A wavy structure bounds the top of the boundary layer
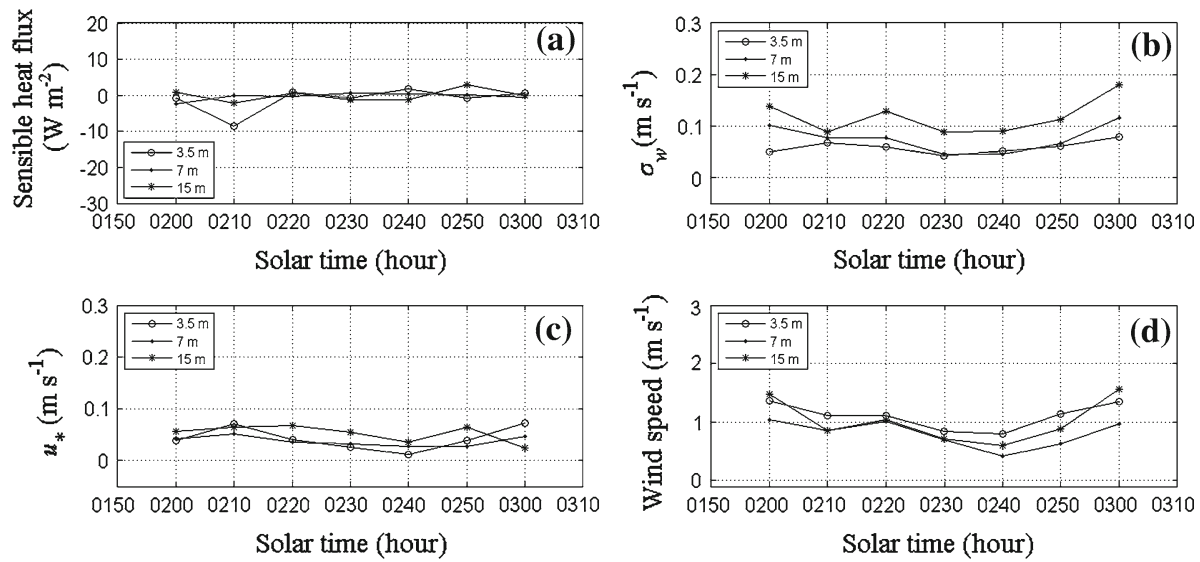

Fig. 7 Day of 6 August 2008 between 0200-0300 ST: a sensible heat flux, b vertical velocity standard deviation, $\mathbf{c}$ friction velocity, $\mathbf{d}$ wind speed (star sonic anemometer at $15 \mathrm{~m}$, full dot sonic anemometer at $7 \mathrm{~m}$, circle sonic anemometer $3.5 \mathrm{~m}$ )

The vertical velocity standard deviation is almost constant, with a maximum mean value (around $0.1 \mathrm{~m} \mathrm{~s}^{-1}$ ) at $15 \mathrm{~m}$ (Fig. 7b). Figure 7c shows the time series of the friction velocity, $u_{*}$, with the value almost constant and less than $0.1 \mathrm{~m} \mathrm{~s}^{-1}$. This trend is observed when the wind speed oscillates around $1 \mathrm{~m} \mathrm{~s}^{-1}$ (Fig. 7d), with similar results obtained for all other days related to group WA.

To show the results obtained for the VS group, the day of 26 September 2008 was chosen. The sodar facsimile record between 2200 and 2400 ST is depicted in Fig. 8. The VS structures have a depth varying with time in a layer of $100 \mathrm{~m}$, while during these hours unusually strong northerly winds are found in place of the local circulation, corresponding to a sudden pressure increase (from 1012 up to $1016 \mathrm{hPa}$ ). In Fig. 9, the time series of the sensible heat flux (Fig. 9a), the vertical velocity standard deviation (Fig. 9b), the friction velocity (Fig. 9c), and the wind speed (Fig. 9d) are shown. All these parameters present a similar trend with a well pronounced peak at $2300 \mathrm{ST}$. As expected, the sensible heat flux is slightly negative during the entire period with values ranging between -10 and $-50 \mathrm{~W} \mathrm{~m}^{-2}$ at 3.5 and $7 \mathrm{~m}$, and between -10 and $-90 \mathrm{~W} \mathrm{~m}^{-2}$ at $15 \mathrm{~m}$. The difference between the levels is the highest in correspondence with the peak value and decreases when the values of the heat flux decrease (Fig. 9a). The vertical velocity standard deviation is plotted in Fig. 9b, with peak values of $0.7 \mathrm{~m} \mathrm{~s}^{-1}$ at $15 \mathrm{~m}$ and about $0.5 \mathrm{~m} \mathrm{~s}^{-1}$ at the lowest levels. The difference between 15 and $7 \mathrm{~m}$ is the greatest at the peak, while a small difference is observed between 3.5 and $7 \mathrm{~m}$. 


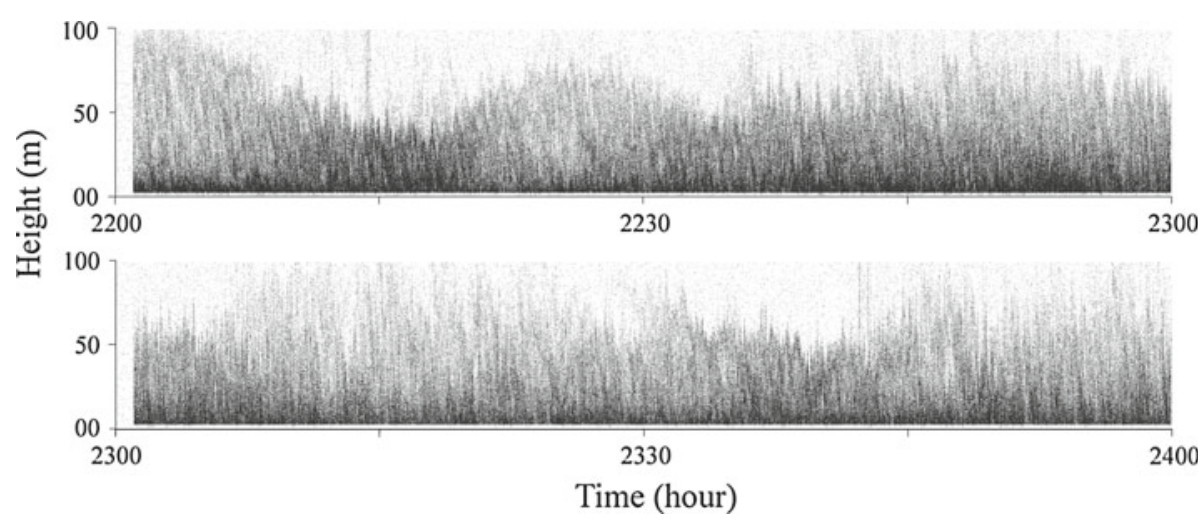

Fig. 8 SLM-sodar facsimile recording for 6 September 20082200 and 2400 ST. Vertical spikes due to the mechanical mixing are observed all the time
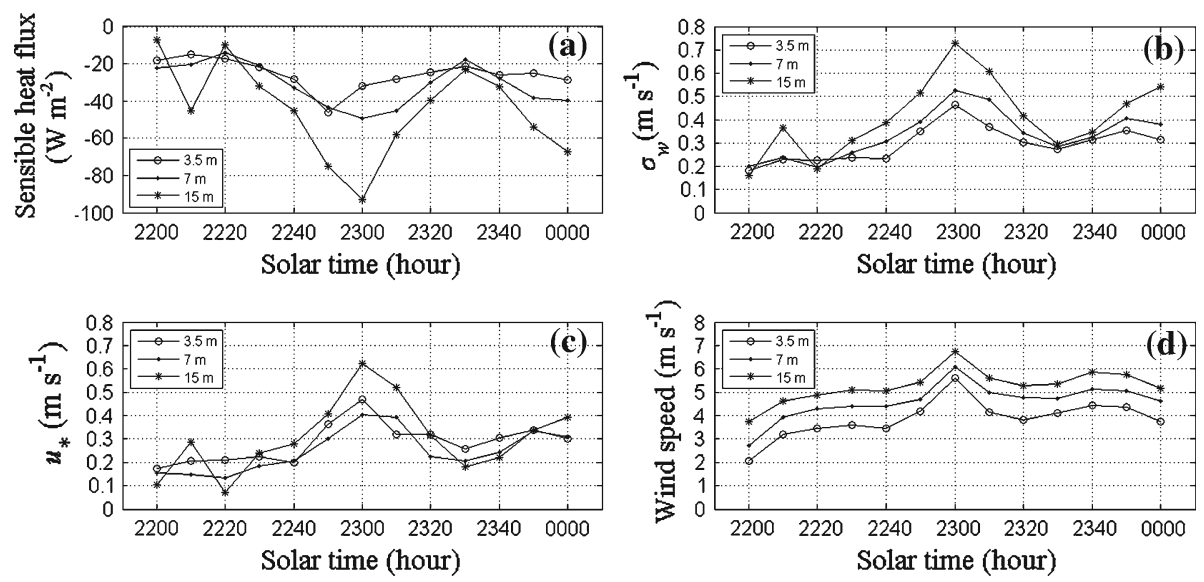

Fig. 926 September 2008 between 2200 and 2400 ST. a Sensible heat flux, b vertical velocity standard deviation, $\mathbf{c}$ friction velocity, $\mathbf{d}$ wind speed (star sonic anemometer at $15 \mathrm{~m}$, full dot sonic anemometer at $7 \mathrm{~m}$, circle sonic anemometer $3.5 \mathrm{~m}$ )

The behaviour of the friction velocity (Fig. 9c) does not change with altitude. Differences are only observed at the peak values, which are $0.4,0.45$, and $0.6 \mathrm{~m} \mathrm{~s}^{-1}$ at $3.5,7$ and $15 \mathrm{~m}$ respectively. Figure $9 \mathrm{~d}$ shows the time series of the wind speed. The same behaviour is observed at all heights, the peaks assuming the values $5.5,6$ and $7 \mathrm{~m} \mathrm{~s}^{-1}$ at $3.5,7$ and $15 \mathrm{~m}$ respectively. The highest variation is observed at $3.5 \mathrm{~m}$.

\section{Summary and Conclusions}

A high-resolution SLM-sodar has been developed at ISAC-CNR. A new configuration for the antennae, the separation between receiving and transmitting chains, and the choice of appropriate running parameters (high-pulse repetition rate, zero delay in the opening of the reception gate, and a short pulse length) allowed the lowering of the start of the first range gate height at $2 \mathrm{~m}$, the reduction of the range gate depth, and an increase in the time resolution 
to $1 \mathrm{~s}$. In this configuration the SLM-sodar has proved to be a very useful system in the study of atmospheric surface-layer turbulent structure and surface-layer horizontal homogeneity and stationarity.

The performances of the SLM-sodar and the conventional sodar have been compared. The black horizontal band in the first $30 \mathrm{~m}$ of the sodar echogram, due to the ringing of the electro-acoustic transducer, is not present in the SLM-sodar since the emission and receiving chains are separated. This setting allows us to highlight the fine structure of the surface layer starting from $2 \mathrm{~m}$ above the ground.

The SLM-sodar was used to study nocturnal surface-layer structure. Two main patterns were identified: stratified layers with waves and non-regular high-frequency vertical spikes. For these categories, the behaviour of the meteorological (wind speed and direction) and turbulent parameters (vertical velocity standard deviation, heat flux, friction velocity) were examined in order to investigate the correlation existing between the turbulent spatialtemporal patterns and meteorological/micrometeorological surface-layer parameters.

Wave structures are observed during clear nights with weak synoptic forcing when the local circulation prevails. Under these conditions the fluxes are almost constant and close to zero. Vertical spike structures are instead observed in a layer whose depth may vary with time, in a 100-m deep layer. The sensible heat flux, the vertical velocity standard deviation, the friction velocity and the wind speed show a similar trend with peaks that correspond with the wind-speed peak.

Depending on the surface-layer turbulence structure the behaviour of turbulent quantities along the vertical may vary with height, and their value may vary depending on the averaging time.

Acknowledgments The authors are grateful to Dr. D. Contini for having made available the sonic anemometer measurements. Thanks go to Sigs. A. Conidi and F. Grasso for the help given during the field experiment. The authors also want to thank the anonymous reviewers and Dr. D. Cavallaro who helped improve the quality of the article.

Open Access This article is distributed under the terms of the Creative Commons Attribution Noncommercial License which permits any noncommercial use, distribution, and reproduction in any medium, provided the original author(s) and source are credited.

\section{References}

Asimakopoulos DN, Helmis CG, Stephanou GJ (1987) Atmospheric acoustic minisounder. J Atmos Ocean Technol 4:345-347

Bonner CS, Ashley MCB, Lawrence JS, Luong-Van DM, Storey JWV (2009) Snodar: an acoustic radar for atmospheric turbulence profiling with $1 \mathrm{~m}$ resolution. Acoust Aust 37:47-51

Contini D, Mastrantonio G, Viola A, Argentini S (2004) Mean vertical motions in the PBL measured by Doppler sodar: accuracy, ambiguities, possible improvements. J Atmos Ocean Technol 21:1532-1544

Contini D, Donateo A, Belosi F (2006) Accuracy of measurements of turbulent phenomena in the surface-layer with an ultrasonic anemometer. J Atmos Ocean Technol 23:785-801

Contini D, Grasso F, Mastrantonio G, Viola AP, Martano P (2007) Performances of a modular PC-based multi-tone sodar system in measuring vertical wind velocity. Meteorol Z 16:357-365

Derbyshire SH (1995) Stable boundary layers: observations, models, and variability. Part I: Modelling and measurements. Boundary-Layer Meteorol 74:19-54

Gryning SE (1985) The Oresund experiment-a nordic mesoscale dispersion experiment over a land-waterland area. Bull Am Meteorol Soc 66:1403-1407

Kaimal JC, Finnigan JJ (1994) Atmospheric boundary layer flow: their structure and measurement. Oxford University Press, New York, 289 pp

Kouznetsov RD (2009) The summertime ABL structure over an Antarctic oasis with a vertical Doppler sodar. Meteorol Z 18:163-167 
Lee X, Massman W, Law B (2004) Handbook of micrometeorology: a guide for surface flux measurement and analysis. Kluwer Academic Publishers, New York, 250 pp

Mastrantonio G, Argentini S (1997) A modular PC-based multiband sodar system. In: Singal SP (ed) Acoustic sounding and applications. Narosa Publishing House, New Delhi, pp 105-116

Mastrantonio G, Fiocco G (1982) Accuracy of wind velocity determinations with Doppler sodar. J Appl Meteorol 21:820-830

McNider RT, England DE, Friedman MJ, Shi X (1995) Predictability of the stable atmospheric boundary layer. J Atmos Sci 20:331-336

Mursch-Radlgruber E, Wolfe DE, Gregg DW, King CW, Neff WD, Sharp KAH, Ruffieux D (1994) NOAA's portable, high-frequency mini-sodar design and first results. Int J Remote Sens 15:325-332

Poulos GS, Bossert JE (1995) An observational and prognostic numerical investigation of complex terrain dispersion. J Appl Meteorol 34:650-669

Seaman NL (2000) Meteorological modelling for air-quality assessment. Atmos Environ 34:2231-2259

Weill A, Klapisz C, Baudin F (1986) The CRPE mini-sodar: applications in micrometeorology and in physics of precipitations. Atmos Res 20:317-333 